\title{
Theodor Koch-Grünberg e a cultura brasileira
}

Fábio Almeida Carvalho ${ }^{a}$

\begin{abstract}
Resumo
Com o objetivo de demonstrar como o baixo investimento no trabalho sistemático e no conhecimento acumulado sobre a diversidade da realidade nacional associado ao apego pela novidade terminológica influem sobre o sistema da inteligência brasileira, este ensaio apresenta a obra do etnógrafo alemão Theodor Koch-Grünberg - misto de viajante, de linguista, de etnógrafo, de antropólogo e de homem de letras - e discute seu lugar entre os construtos da produção da inteligência brasileira.
\end{abstract}

Palavras-chave: Theodor Koch-Grünberg, cultura brasileira, século XX 


\section{À guisa de introdução}

O baixo investimento no trabalho sistemático de pesquisa sobre a diversidade da realidade nacional e o apego pela novidade terminológica parecem ser responsáveis, em larga medida, pela existência de grandes lacunas na historiografia brasileira. Em razão de a obra de Theodor Koch-Grünberg ainda ser pouco reconhecida pela inteligência que floresce nos campos da literatura, da história, da sociologia, dentre outros que integram o grande campo das humanidades, ainda está por ser devidamente estabelecida a sua contribuição para o desenvolvimento da cultura brasileira do século XX.

Partindo do pressuposto de que a obra do viajante alemão deixou marcas profundas na produção tanto das nossas belasletras quanto das nossas ciências sociais e humanas e que exatamente por isso merece maior atenção que aquela que até o momento lhe tem sido dispensada, o ensaio tem o objetivo de fazer uma espécie de balanço crítico sobre sua participação no desenvolvimento da cultura brasileira moderna.

Reconhecendo, pois, a robustez da obra de Theodor Koch-Grünberg e a necessidade de estabelecer seu devido lugar entre os construtos da nossa inteligência, o ensaio propõe discutir como a obra derivada das suas viagens pela Amazônia contribuiu para o desenvolvimento, em diferentes dimensões, da vida cultural brasileira no período. Antes, porém, é necessário abordar, mesmo que en passant, a questão da especificidade e do consequente lugar da atividade dos viajantes, bem como de que maneira a Amazônia sempre esteve na pauta de discussão sobre o processo de desenvolvimento das ciências e das artes modernas, senão também sobre a compreensão dos sentidos atribuídos à Amazônia na construção da nacionalidade brasileira.

\section{Amazônia: viagens, viajantes e outros bichos}

Aquilo que em geral é designado como "obra dos viajantes" é produto de diferentes tipos de atores sociais, com história de vida e funções intelectuais altamente diferenciadas, porque estes ocupam diferentes posições na cultura de cada época. Com esquemas diversos de financiamento e, por conseguinte, com mecanismos distintos para divulgação 
dos resultados de suas pesquisas, esses homens participam diferentemente das formas de retribuição de seus trabalhos, que tem a ver com a concessão de honrarias, com a ocupação de cargos públicos e de posição de destaque no campo das ciências em que atuam, dentre outros mecanismos. As crônicas produzidas por naturalistas, cientistas, filósofos e literatos são um tipo de produção realizada por certos atores sociais de acordo com um conjunto de regras e expectativas historicamente definidas e muito heterogêneas.

Não obstante a heterogeneidade, ou talvez graças a ela, não consiste nenhuma novidade reconhecer a posição privilegiada das obras e das ideias dos viajantes, tanto no que diz respeito à realização de interpretações com pretensões científicas, quanto no que concerne à produção de obras de imaginação. Produzido desde os primórdios do processo de colonização, este vasto conjunto textual foi assumindo posição de destaque e, em razão disso, gozando do estatuto de fonte não apenas para o campo dos discursos filosóficos, literários, etnográficos e antropológicos, senão também da história, da geografia e da sociologia, que muitas vezes nele se apoiam e dele retiram não apenas suas hipóteses, mas também suas dúvidas e suas certezas, a seiva que os fortalece, enfim.

Não obstante, a ausência de maior aprofundamento do processo de identificação das fontes historiográficas primordiais sobre este espaço-chave da interpretação do nacional ainda gera graves lacunas no estudo da formação política, social e cultural da Amazônia e, por conseguinte, do Brasil. Afinal, dentre todos os espaços do Novo Mundo, talvez nenhum tenha excitado tanto a curiosidade e a imaginação dos homens da ciência e da criação do espírito quanto o amazônico, que assumiu o papel de repositório ideal dos elementos necessários para as condições de felicidade de projeção, de execução e de divulgação de uma viagem interessante, digna de ser financiada e de ser apresentada e contada, em termos de resultados.

\section{Segundo Renan Freitas Pinto}

A Amazônia [...] esteve, desde o início da construção filosófica do mundo moderno, presente nas reflexões em torno de temas como o surgimento da sociedade e do Estado, do reconhecimento das desigualdades entre os 
homens e os povos [...], e continua a fornecer alimento para a recriação de novas polarizações, como a recriação do bom selvagem em ideias como a de "povos da floresta" e de "ribeirinhos", portanto de um novo romantismo social. (FREITAS, 2008, p. 15)

A Amazônia sempre assumiu a condição de elemento de primeira importância na pauta de produção do pensamento ocidental, ocupando a mente tanto daqueles que se envolveram diretamente com a região, quanto daqueles que não trataram diretamente dela - todos comumente envolvidos com as "ideias centrais que tem sido utilizadas para descrevê-la, pensá-la, interpretá-la" (PINTO, 2008, p. 15). A paisagem e a vida do/ no espaço amazônico se tornaram, desde cedo, locus ideal para manifestação dos discursos dos viajantes, fossem eles afiliados ao âmbito das ciências ou da imaginação criativa.

Por isso, também se mostrou elemento fundamental para a construção das interpretações sobre a unidade e a diversidade brasileira, em diferentes dimensões e aspectos, com desdobramentos que se fazem presentes ainda nos dias de hoje. Aprofundar o conhecimento destas fontes pode, talvez, não apenas apontar e elucidar novas e velhas questões para historiadores, sociólogos, geógrafos e demais cientistas sociais, mas também ser fonte de novos estímulos para o terreno da criação artística em âmbito regional, nacional e internacional.

Ana Pizarro (2005) propõe uma síntese da construção discursiva da Amazônia num processo que se estrutura em quatro estágios. No primeiro, podem ser agrupados nomes como o de Carvajal, Pedro Teixeira, Daniel Dantas e Samuel Fritz, dentre muitos missionários, e tem como enunciadores os "descobridores", os primeiros ocupantes e as sociedades científicas. Tem como meio de divulgação as crônicas e os relatos de viagem, que conformam uma literatura de corte geográfico, eivada de aspectos eróticos, sociais e, ainda, por um elemento de cunho empresarial. Esta vertente discursiva se caracteriza por uma mescla de imaginação liberta e de informação detalhada, pela mistura de notícias sobre o País da Canela e sobre El Dorado, e de informação sobre a geografia, as condições de navegação e de ocupação e de domínio dos territórios.

Acelerada a partir do século XVIII, com a estruturação do campo das ciências, que nutre a pretensão a maior grau de racionalidade - apesar da persistência de elementos 
fantasiosos -, o teor e a fatura das elocuções dos viajantes se alterou e conformou outro tônus discursivo sobre a Amazônia. Cientistas, botânicos, filósofos e afins, como La Condamine, Henry Walter Bates, Alfred Wallace, Humboldt e Barbosa Rodrigues, dentre outros, ajudaram a dar os contornos da imagem construída para a Amazônia enquanto grande repositório da fauna e da flora do planeta. Nesse sentido, a Amazônia pode ser apontada como decisiva para a construção do pensamento científico do século XVIII.

No final do século XIX, emerge um terceiro tônus discursivo sobre a Amazônia, marcado pelas vozes que enunciam no contexto da exploração da borracha e da delimitação das fronteiras nacionais das nações americanas do Sul, em que as atividades comerciais de grandes empresas estrangeiras se sobrepuseram às atividades missionárias e aos interesses marcadamente científicos. Entra em cena o empenho norte-americano e os interesses comerciais pelo extrativismo em grande escala, decorrente da economia da borracha, que se entrelaça com a corrente de pensamento de afirmação das nações por meio da delimitação das fronteiras. De corte marcadamente positivista, esse discurso tem como enunciadoras principais as fontes governamentais e encontra na obra do peruano Valdez Lozano sua expressão mais acabada.

Na mesma época aflorou outro filão discursivo marcado pela denúncia da situação em que viviam e trabalhavam os seringueiros e os caucheiros (a alimentação precária e a sujeição a doenças, o trabalho penoso e escravizante e, sobretudo, a forte angústia da solidão), que consolidou a concepção de Inferno Verde para o espaço amazônico. Neste grupo discursivo constam nomes como o de Ferreira de Castro e de Euclides da Cunha.

O esquema histórico-linear que estrutura a exposição da ensaísta chilena não deixa de ser interessante pela síntese do processo histórico amazônico. Todavia, talvez ele possa ser concebido não mais do que como recurso narrativo - uma vez que os períodos por ela apontados parecem antes ser cumulativos que sucessivos. Demais, a hegemonia de um deles em certo período histórico certamente não significa sua exclusividade.

Não se pode, contudo, deixar de reconhecer que, nos últimos séculos, tem-se produzido e acumulado conhecimento sobre o homem e a sociedade amazônica em sua relação com 
a natureza - com especial destaque para os povos indígenas e para os caboclos e ribeirinhos. Mas se muito tem sido dito sobre a Amazônia, líquido e certo é que muito falta ser feito para que se possa chegar a um patamar aceitável de conhecimento sobre essa zona que tanta importância vem desempenhando no desenvolvimento das ideias sobre a ciência e a humanidade.

Demais, ainda precisa ser devidamente aprofundada a questão de sua participação em relação à nação brasileira, uma vez que a compreensão de "território distante dominado pela floresta, [com] enorme bacia fluvial e inúmeras populações indígenas, portanto, de exploração e integração econômica e política mais difícil do que as demais parcelas do território colonial" (PINTO, 2008, 227), ainda carece de investigações mais densas que melhor a apresentem e expliquem.

Estas considerações iniciais sobre o trabalho dos viajantes e seu derivativo para a construção discursiva da Amazônia e do Brasil servem para fazer a apresentação de Koch-Grünberg, cuja obra se erigiu a partir das viagens pela Região. No passo seguinte, abordaremos o tipo de viagem empreendida e a especificidade da prática etnográfica que orientou sua execução e conformou os seus resultados.

\section{Alguns dados biográficos}

Em 1898, quando Koch-Grünberg foi convidado por $\mathrm{H}$. Meyer, um dos homens mais influentes da cultura alemã de então, para cuidar da parte linguística da segunda expedição científica que realizava ao Xingu, ele era apenas um jovem filólogo recémformado que nutria o desejo de desbravar a exótica América do Sul. Embora malograda, por conta de um naufrágio que quase dizimou a comitiva científica da expedição, esta viagem motivou a publicação de Animismus der Südamerikanischen Indianer [Sobreo animismo dos índios sul-americanos], chamou a atenção do círculo da etnologia alemã e rendeu estágio no Museu Etnográfico de Berlim ao aspirante a etnógrafo.

O reconhecimento profissional viria depois da segunda expedição, feita aos rios Negro e Japurá, entre 1903 e 1905, que rendeu a publicação, em dois volumes, em 1909 e 1910, de Zwei Jahre unter den Indiarnern, Reisen in Nordwest-Brasilien [Dois anos entre os índios do Brasil]. Mas, apesar de sua incontestável importância documental e de reconhecidamente ser fonte 
primordial sobre a região no início do século $X X$, a obra permaneceu quase desconhecida dos brasileiros durante várias décadas. Somente em 2005 o texto foi publicado em português, pela editora da UFAM, que providenciou sua tradução.

Já então etnógrafo de renome, entre 1911 e 1913, KochGrünberg viajou para o rio Branco, na tríplice fronteira entre Brasil, Guiana e Venezuela, região pouco explorada e sobre a qual se dispunha de escasa informação. ${ }^{1} \mathrm{O}$ resultado desse empreendimento foi a publicação dos cinco volumes que relatam em diferentes gêneros a experiência do viajante alemão na expedição quase solitária que fez ao norte do Amazonas e ao sul da Venezuela: Vom Roroima zum Orinoco: Ergebnisse einer Reise in Nordbrasilien und Venezuela in den Jahren [Do Roraima ao Orinoco: Observações de uma viagem pelo norte do Brasil e pela Venezuela entre os anos de 1911 e 1913].

Na quarta viagem feita ao Brasil, na condição de integrante da comitiva de Hamilton Rice, Theodor KochGrünberg morreu na comunidade Vista Alegre, às margens do Rio Branco, perto da cidade de Caracaraí, em Roraima (não no Acre, como em geral se pensa), provavelmente acometido por malária. A morte prematura desse viajante contumaz da Amazônia impediu que ele continuasse a fornecer lenha para a compreensão da geografia e do seu processo histórico amazônico. Ele dedicou a vida ao estudo das culturas das populações do norte do Amazonas e construiu uma obra relevante para o grande campo das ciências sociais - mas também para a literatura brasileira.

1 Antes dele, as informações mais consistentes sobre a região foram colhidas pelos irmãos Richard e Robert Schomburgk, que se notabilizaram pela qualidade dos dados etnográficos, linguísticos e de história natural que reuniram como funcionários da Coroa britânica em viagem pelo BrasilGuyana-Venezuela, com a finalidade de reunir elementos para a arbitragem da fixação de fronteiras. A tradição etnográfica de nossos dias a nomeia como região circum-Roraima.

\section{Theodor Koch-Grünberg e a etnografia}

Para Nádia Farage e Paulo Santilli, o quadro teóricometodológico que presidiu a realização da obra de KochGrünberg se inscreve no campo antropológico alemão que

[...], entre fins do século XIX e início do XX, [...] dedicou atenção às sociedades sul-americanas, área abandonada pela antropologia francesa e pela inglesa, que então se voltavam à Oceania e à África. Tal interesse intelectual alemão pelas terras baixas sul-americanas, [...], deveu-se, de um lado, à proeminência dos naturalistas na configuração acadêmica das ciências humanas e naturais na Alemanha; e, de outro e o que é mais importante -, ao baixo impacto da expansão 
imperialista alemã que, somado à influência tardia do iluminismo no país recém-unificado, fez que a representação do exótico se constituísse, exponencialmente, na imagem setecentista do selvagem sul-americano. $\mathrm{O}$ americanismo dos anos 20-30 do século XX, [...], foi [...] fruto do pensamento intelectual alemão [...] marcado por interrogações de cunho evolucionista e difusionista. Koch-Grünberg permaneceu preso a tais preocupações teóricas que [...] logo tornarse-iam anacrônicas diante da antropologia que nascia na França, na Inglaterra e nos E. Unidos no período. (FARAGE \& SANTILLI, 2006, p. 14)

Erwin H. Frank (2005, p. 559-584) apresenta o pano de fundo em que foi decalcada a vida intelectual, acadêmica e científica da Alemanha da segunda metade do século XIX até a década de 1920, e examina o modo pelo qual um filólogo desconhecido, como o jovem Koch-Grünberg, fez carreira numa ciência que nunca tinha estudado, a etnologia, e, mesmo sem ter feito contribuições teórico-paradigmáticas de destaque, foi obtendo, “[...] em rápida sequência, sempre novas e mais elevadas honrarias, títulos e cargos, tanto no âmbito museológico como no campo acadêmico, [...]", sendo rapidamente reconhecido pelo seu "[...] excepcional talento como etnógrafo, ou seja, sua rara capacidade de imaginar, organizar e levar a cabo viagens de pesquisa [...] e de resumir os resultados em textos [...]".

Koch-Grünberg pagava tributo a um projeto que começou a ser moldado no fim do século XVIII, sob a influência da obra de Wilhelm von Humboldt, que defendia a tese holística (em contraponto às generalizações iluministas) de que o caráter da humanidade como espécie (Gattungscharakter) realiza-se historicamente numa variedade quase ilimitada de caracteres nacionais (Völkscharakter), e que isso reflete nos costumes, nas crenças, na língua e nas artes de cada povo e de cada época.

Para Erwin H. Frank, esse projeto da intelligentsia alemã exibe um lastro que se estende desde Herder até a ruptura provocada pelo pensamento de Kant entre as ciências naturais e sociais, ocorrido em meados do século XIX. Como bem resume o autor, tratava-se da Völkerkunde/Völkskunde (Etnologia/Antropologia) alemã, que encerrava um programa epistemológico centrado "na tentativa de seus criadores [...] de resolverem cientificamente a questão [...] da causa ou razão de ser das diferenças e semelhanças entre povos distantes no tempo e/ou no espaço". 
Essa concepção da prática antropológica se cristalizava por meio de uma praxe de pesquisa e documentação etnográfica que buscava reunir a maior quantidade de dados para a identificação de ideias universais por trás de formas particularizadas de povos concretos (Völkergedanken). Para Frank, a abordagem Völkerkunde se assentava sobre três premissas básicas: a) a de que a cultura se expressa em qualquer e em todo ato, fato e produto sociocultural; b) parte das variações concretas entre culturas se dá em razão das diferenças ambientais em relação às diferenças na constituição (psico) física dos integrantes de duas ou mais culturas; c) a dinâmica de qualquer cultura é genuinamente "histórica".

Agenciada pelo método Völkerkunde e, por isso, comprometida com o objetivo de compulsar relatos de viagem e de estruturar repositórios de folclore, a empreitada de Koch-Grünberg se consubstanciava enquanto prática etnográfica empenhada na montagem de coleções de artefatos diversos - compósitos de elementos materiais e imateriais, estruturadores e conformadores das culturas estudadas. Em última instância, objetivava a reproduzir no rico ambiente dos museus da Europa, as condições de vida que havia experimentado durante a viagem.

Daí a ambição de coletar dados quase à exaustão. E disso resultou que Koch-Grünberg reuniu nos cinco volumes de Vom Roroima zum Orinoco múltiplas e variadas observações da viagem que fez aos campos naturais de Roraima: o primeiro volume contém o relato de viagem; o segundo apresenta a coleção de mitos e lendas Macuxi, Taurepang e Wapichana; o terceiro é dedicado à etnografia Taurepang e à análise musicológica das canções desse povo; o quarto é dedicado à linguística comparativa de cerca de três dúzias de línguas indígenas distintas das regiões dos rios Branco e Orinoco; o quinto volume apresenta um ensaio fotográfico, espécie de contribuição ao campo da antropologia física.

Ao constatarmos a verdadeira profusão de gêneros - índice do esforço totalizante de abarcar múltiplas facetas de culturas aparentadas -, não podemos senão concordar com Erwin H. Frank, que julga ser a Völkerkunde um projeto humanamente impossível de ser realizado em termos científicos.

Assumir uma perspectiva de captação da realidade em "grande angular", conforme diagnostica Frank, resultou a ineficiência do método da Völkerkunde alemã, que condenava o etnógrafo a reunir de forma itinerante o máximo que pudesse de noções, ideias, ações e produtos de ações sociais de um povo, a fim de realizar 
${ }^{2}$ FARAGE, Nádia; SANTILLI, Paulo. Introdução. In: $\mathrm{KOCH}-$ GRÜNBERG, Theodor, Do Roraima ao Orinoco. Observações de uma viagem pelo norte do Brasil e pela Venezuela durante os anos de 1911 a 1913. São Paulo: Editora UNESP, 2006. o trabalho de uma antropologia comparativa marcada, em traços gerais, pela superficialidade - haja vista que acabava por impedir o conhecimento mais profundo da totalidade das dinâmicas internas das sociedades estudadas. A ânsia de observar e documentar variações étnicas de grupos culturais distintos assumiu a forma de uma antropologia comparativa de caráter muito amplo, porque "não havia ideia, ação ou objeto material privilegiado, [...], uma vez que tudo era da mesma maneira 'culturalmente constituído' e igualmente importante". (FRANK, 2005, p. 574)

Koch-Grünberg talvez possa ser apontado como o exemplo mais bem-acabado desse método de abordagem antropológica, já que logrou, com "talento, energia e paciência" sem par, "acumular quantidades deveras impressionantes de dados etnográficos, em geral de excelente qualidade e em um tempo mínimo". Porém, conforme avalia Frank, a diversidade mesma da produção do etnógrafo alemão seria índice da derrocada da Völkerkunde, uma vez que era humanamente impossível um projeto ambicioso, generalizante e de tão amplas pretensões lograr êxito, e que entrava em crise, paradoxalmente, no momento mesmo em que conseguia sua maior e mais bem-acabada realização: a publicação dos cinco volumes de Vom Roroima zum Orinoco. (FRANK, 2005, p. 559-584)

\section{O legado}

Ainda que não tenha produzido pensamento teóricometodológico de maior envergadura, não se pode deixar de reconhecer, primeiramente, que Theodor Koch-Grünberg fez um registro impressionante e minucioso daquilo que se pode definir como "socialidade macuxi", como bem atestam Nádia Farage e Paulo Santilli no prefácio à edição brasileira de Do Roraima ao Orinoco. ${ }^{2}$

O tomo I contém o relato, ou antes, a narrativa da viagem, e registra minuciosamente numa prosa a um só tempo pictórica, forte e envolvente, a paisagem, a fauna e a flora, senão também a vida dos indígenas e das demais populações locais do rio Branco. Nas suas páginas abundam ricas observações sobre o ritmo da vida e sobre as múltiplas relações mantidas pelos diferentes grupamentos humanos que ocupam este território.

Trata-se de documento indispensável à leitura de quem quer conhecer um cadinho melhor os modos de organização da vida que ocupava este espaço tão pouco conhecido da realidade 
brasileira. Para José Mindlin (In Koch-Grünberg, 2006, p. 9), com a tradução e publicação em português, ocorrida em 2006, quase cem anos depois de realizada a viagem, portanto, o Brasil resgatou uma "dívida" importante, dentre outras que vão "continuar pelos tempos afora".

Mas, como bem notaram Farage e Santilli (2006, p. 1213), a prática etnográfica que conforma sua produção é muito estranha aos padrões contemporâneos do fazer etnográfico. Assim ocorre, por exemplo, porque, dentre outros aspectos, "em vez de deixar-se levar pelo ritmo da vida indígena [como sói ocorrer desde Malinowski até os dias de hoje], é KochGrünberg quem, com sucesso ou não, mobiliza as pessoas, às vezes a aldeia inteira, e as traz para sua própria aventura".

Consideradas estas condições, talvez realmente não faça muito sentido acreditar que, em tempos de predominância da noção de "politicamente correto" como aspecto primordial da avaliação cultural, a (hiper) sensibilidade de muitos leitores seja compatível com a fruição da obra do etnógrafo alemão. Mas esse estado de coisas não pode ser suficiente para tornar refutável sua contribuição para o desenvolvimento do conhecimento científico em campos diversos como a etnografia, a antropologia e a história regional.

Mas como toda leitura, esta também tem de ser operacionalizada em contraponto: em meio ao enorme volume de informações, a obra de Koch-Grünberg ajuda a desfazer concepções equivocadas sobre as populações indígenas, as quais se mantém vigentes ainda em nossos dias. Tal é o que acontece, por exemplo, quando ajuda a desmentir a falácia de que não existe, para os indígenas, a ideia de posse e de propriedade, como ocorre na passagem que segue, reproduzida de Dois anos entre os indigenas...:

Eu tinha trazido algumas pequenas mercadorias para troco, mas a gente não estava disposta para negociar. Eu teria gostado de adquirir vários objetos, mas estes pertenciam a outra gente que ainda estava na festa em Cururu-Cuára. A propriedade alheia é respeitada rigorosamente. Ninguém vende nem uma bagatela que tenha um outro dono. Ninguém aceita um pagamento destinado a outrem. (KOCHGRÜNBERG, 2005, p. 85). 
É, pois, na condição de homem e de cientista de seu tempo, que reuniu as qualidades de etnólogo, de antropólogo, de filólogo, mas também de historiador, que Koch-Grünberg pode ser definido como um viajante que marcou de forma definitiva o quadro ortodoxo da etnografia roraimense e brasileira no século XX. Para Renan Freitas Pinto (2005, p. 246), o conhecimento da obra de Koch-Grünberg, do ponto de vista dos indígenas, "torna possível a reconstrução histórica de sua organização social e identidade étnica, de seus movimentos em relação aos seus territórios e aos processos demográficos de seus respectivos grupos, possibilitando, na atualidade, verificarmos o que permaneceu, o que mudou, e mesmo, o que [...] desapareceria inexoravelmente".

Importante contribuição se encontra no tomo II, onde o viajante alemão coletou um considerável repertório de narrativas, cantos e fórmulas mágicas de raro valor cultural e artístico, além de uma considerável coleção de objetos e artefatos etnográficos, espalhados pelos museus alemães. $\mathrm{O}$ conjunto reunido no volume II é com certeza um precioso monumento textual indígena - verdadeira raridade, que permite uma aproximação ímpar das formas textuais indígenas do extremo norte da América do Sul.

O lendário colhido Koch-Grünberg é composto de exatamente cinquenta textos em geral de breve extensão poucos apresentam entrechos mais distendidos. Mas somente as doze primeiras narrativas têm Makunaíma e seus irmãos como fio condutor dos eventos: 1 - "A árvore do mundo e a grande enchente" (versão Arekuna); 2 - "A árvore do mundo e a grande enchente" (versão Taurepang); 3 - "Incêndio Universal"; 4 - "Feitos de Makunaíma"; 5 - "Outros feitos de Makunaíma"; 6 - "Façanhas de Makunaíma"; 7 - "Como a arraia espinhosa e a cobra venenosa chegaram ao mundo"; 8 - "Makunaíma e o rapaz da árvore Samaúma"; 9 - "Makunaína no laço de Piaímá"; 10 - "Makunaíma e Piaímá"; 11 - "Morte e ressurreição de Makunaíma”; 12 "Makunaíma e Waimesa-pódole”.

Nas demais trinta e oito narrativas, há grande diversidade de personagens, protagonistas e antagonistas, que assumem a forma de homens, de animais, de monstros, bem como de qualidades e de defeitos humanos. Elas são estruturadas a partir de núcleos temáticos diversos que denunciam o quanto o etnógrafo estava comprometido com encontrar exemplares 
narrativos que comprovassem a suposta "maneira infantil" de a mente primitiva representar e explicar o mundo.

A favor de sua obra pesa que este volume representa contribuição fundamental tanto porque registra um material que corria o risco de ir empalidecendo cada vez mais, em razão das contingências históricas, quanto porque ajuda a resguardar parte do patrimônio imaterial sempre ameaçado de desaparecimento.

Neste passo, posso testemunhar, a partir da experiência acumulada como professor de um curso de formação de professores indígenas, na Universidade Federal de Roraima, sobre a importância desse material para a salvaguarda da cultura imaterial dos povos indígenas do rio Branco. Ocorre que, por conta do contato e da sedução exercidas pela cultura ocidental, os elementos típicos das narrativas indígenas se transformaram desde então de forma sensível, sobretudo por conta da força do substrato religioso. Demais, como demonstro no meu recém-lançado Makunaima $\approx$ Macunaíma, contribuições para o estudo de um herói transcultural (Carvalho, 2015), temos, nos dias de hoje, uma lógica estruturante narrativa muito distante daquela que encontramos no conjunto coletado por Koch-Grünberg e por outros viajantes que recolheram os mesmos mitos e lendas à época.

Trata-se de questão interessante para os desdobramentos do atual momento do pensamento interpretativo do tecido social brasileiro, no qual se confere tanto valor às diferenças e às identidades marcadas, ao fortalecimento de identidades étnicas específicas e diferenciadas, enfim. Ao cotejar os textos colhidos por Koch-Grünberg com outros colhidos hodiernamente, o analista contemporâneo dessa questão se vê diante de um verdadeiro imbróglio, uma vez que os elementos típicos das narrativas indígenas, tais como a lógica narrativa aparentemente disparatada, a ambiguidade fundadora do caráter e das ações dos heróis, por exemplo, são, amiúde, substituídos por elementos eivados da fatura cristã, em que prevalece o maniqueísmo dual dos heróis e das situações narrativas. Daí sobressair gritante senso de desproporção entre os discursos defensores da "pureza étnica" e os artefatos narrativos colhidos nos dias de hoje para fins de exemplificação e de sustentação. 
Essa é uma dimensão de suma importância, tanto para os indígenas da região circum-Roraima quanto para todos os interessados pelas textualidades indígenas que, por intermédio do seu trabalho, têm possibilidade de acesso garantido a parte do patrimônio imaterial de seus ancestrais, sem a mediação das camadas de sedimentos culturais mais modernas e que tanto alteram a forma e o conteúdo de seus construtos.

Considerando o que acima foi dito, podemos supor que a pouca atenção dedicada à obra de Koch-Grünberg parece ser resultante da transformação por que passava o quadro das ciências humanas, pois, à época, o interesse pelo americanismo declinava no horizonte de expectativas da academia e o modelo Volkerkunder se via ofuscado pelas transformações por que passava a antropologia naquele momento. Diante das inovações do paradigma das ciências sociais, o modelo etnográfico Volkerkunder se apresentava como anacrônico e "fora de moda".

Mas a publicação do material colhido na viagem não passou despercebida por um jovem intelectual que, na condição de líder de um movimento de grande repercussão social, cultural e histórica, nos idos de 1920, estava empenhado em definir o caráter nacional da cultura brasileira. Foi a partir de Koch-Grünberg que Mário de Andrade compôs o enredo de Macunaíma (1928), obra-símbolo do Modernismo brasileiro. Aqui entramos no âmbito da discussão sobre a maneira como as obras vão vincando seu espaço, criando seu público e delimitando as esferas da influência que exercem ao longo do tempo e em diferentes lugares. Dessa perspectiva, a reação de $M$. de Andrade à leitura dos Mitos e lendas dos índios Taulipang e Arekuná é indício do legado de Koch-Grünberg à cultura brasileira.

Os arquivos depositários do acervo de M. de Andrade, mantidos pelo Instituto de Estudos Brasileiros da Universidade de São Paulo, comprovam que, no seu escritório de trabalho, o escritor modernista possuía quatro dos cinco volumes de Vom Roroima zum Orinoco - somente o volume IV não foi encontrado

${ }^{3}$ ANDRADE, Mário de. Macunaíma; o herói sem nenhum caráter. Edição crítica de Telê Porto Ancona Lopez. Rio de Janeiro; São Paulo: LTC; Secretaria da Cultura, Ciência e Tecnologia de São Paulo, 1978, p. 217-224. em sua biblioteca. No "Prefácio escrito imediatamente depois de terminada a primeira versão" de Macunaíma, datado de 27-III-1928, Mário de Andrade declara que, quando matutava em descobrir o máximo que pudesse a "entidade nacional dos brasileiros", topou com Makunaíma no alemão de KochGrünberg e, segundo confessa..., literalmente "gozou". ${ }^{3}$ 
Ao encontrar com Makunaíma nas páginas de Vom Roroima zum Orinoco, Mário de Andrade gozou mesmo foi da sensação da grande descoberta, e teve a imediata iluminação eufórica dos que se deparam com novo e rico filão, potencialmente capaz de prover de matéria-prima o projeto em que ele estava empenhado desde muito: moldar uma solução artística e literária para a construção de uma cultura própria para o Brasil.

Para Telê Ancona Lopez (In ANDRADE, 1997, p. XXVII) provavelmente "o ano da leitura e o primórdio da escritura de Macunaíma é fornecido de forma cifrada na "Carta pras Icamiabas", capítulo IX: "Trinta de Maio de Mil Novecentos e Vinte e Seis, em São Paulo". Esse momento marcaria a proto-história da gênese da obra, uma vez que as "páginas de Vom Roroima zum Orinoco são para o leitor/autor [Mário de Andrade] como páginas de caderno próprio, onde os olhos se detêm sem cerimônia no que escreve, dando à mão liberdade de rasurar". ${ }^{4}$ As páginas desse exemplar constituem locus genesis privilegiado porque guardam vestígios do modo de apropriação e evidenciam o processo de transculturação daquele que se tornou "herói da nossa gente".

Mythen und Legenden der Taulipang- und Arekuná-Indianern acabou por funcionar como elemento de motivação não apenas para a realização da empreitada de consubstanciar em obra de ficção o compromisso de definição do caráter brasileiro, mas também por servir como uma espécie de "livro-guia" na construção da rapsódia, dado que fornece o tema principal e os motivos centrais, bem como muitos dos temas secundários, além de uma farta gama de outros elementos de linguagem que compõem a obra do escritor brasileiro. A esses motivos principais, articuladores dos episódios no desenvolvimento do entrecho, se agregam outros tantos e diversos colhidos em múltiplas fontes eruditas e populares.

No que tange ao tema central dos episódios de cada capítulo, Mário de Andrade (1997, p. 490) afirma, em carta a Carlos Drummond de Andrade, datada de 18 ou 19 de janeiro

${ }^{4}$ LOPEZ, Telê Ancona, "Nos caminhos do texto". In: ANDRADE, Mário de. Macunaíma Madrid; Paris; México; Buenos Aires; São Paulo; Lima; Guatemala; San José de Costa Rica, Santiago de Chile, ALLCA XX, 1997, p. XXVII de 1927, que "não tem senão dois capítulos meus no livro" (os capítulos VIII, "Macumba", e IX, "Carta pras Icamiabas"). Dentre os demais, quase em sua maioria foram aproveitados do lendário de Koch-Grünberg, com exceção dos temas centrais dos capítulos IV e XIII, que são fornecidos por Capistrano de Abreu e Couto de Magalhães. Sem concorrer para a estrutura geral dos capítulos, boa parte dos temas foram tomados do 
Poranduba Amazonense, de Barbosa Rodrigues, e das Lendas Amazônicas, de J. Oliveira Coutinho. Esses, dentre outros, como Ao som da viola, de Gustavo Barroso, e de Contos Populares, de Sílvio Romero, forneceram os motivos e quase tudo o mais para que Mário de Andrade construísse a obra reconstruindo a imagem da personagem.

Cavalcanti Proença faz minucioso levantamento das características do herói, que é estruturado a partir da junção de uma infinidade de personagens. Para ele, Macunaíma

[...] encarna uma variedade de outras personagens, ora boas, ora más, ora ingênuas; quase sempre ingênuas". [E acrescenta]: no cap. I, ele é o Jabuti que no lendário de Grünberg caça o Tapir na armadilha, a seguir é Kalavunseg, quando inventa que viu timbó na beira do rio. E assim continua livro adentro, sendo o Pe. Anchieta quando viaja à sombra das asas dos papagaios e araras, Wewe dos taulipangs, o jabuti da festa no céu. Depois da Macumba, Macunaíma é o próprio Mário que sai em companhia de Manuel Bandeira, Ascenso Ferreira e outros; e logo se torna Akalapizeima, na ilhota da Guanabara. É o carão que vai roubar o talismã do Jurupari, volta a ser Kalavunseg, mentindo que caçou veados, em vez de ratos, é o jaguar logrado pelo chuvisco, é um tolo logrado por Konéwo, é o filho de Kainkewe, quando se vê coberto de carrapatos, é outros heróis e outros vilões variabilíssimos no correr do livro. (PROENÇA, 1978, p. 9)

Disso resulta um personagem cimentado da união de caracteres oriundos de diferentes tribos indígenas, de diversas personalidades da história brasileira, de diferentes épocas e regiões do Brasil. É obedecendo, pois, a esse compasso - em que a estratégia principal se consubstancia em universalizar por meio do que há de mais genuinamente brasileiro - que, segundo M. Cavalcanti Proença (1978, p. 60), “O herói é da nossa gente de todos os quadrantes, tem hábitos, crendices, alimentação, linguagem isentos de qualquer traço predominante. Incorpora sem ordem nem hierarquia as características de cultura, diferenciadas nas várias regiões brasileiras".

Assim, se parte da importância desempenhada por Mário de Andrade no cenário da cultura brasileira do século $X X$ deriva de seu investimento maciço no conhecimento profundo das fontes primárias sobre o Brasil, outra parte deriva de ter 
sido ele capaz de vislumbrar o valor desse material e, por acréscimo, de ter sido dotado de suficiente genialidade, capaz de garantir a recriação, em alto nível, do material colhido no âmbito da cultura popular na esfera da cultura erudita.

O caso não deixa de ser elucidativo para se pensar na já tão propalada pobreza da cultura amazônica e, por que não, brasileira - que em larga medida decorre da falta de conhecimento e histórico mais profundo, por conseguinte, da pouca consciência histórica dos nossos criadores de cultura. Em última instância, o exemplo de Mário de Andrade, um brilhante escritor paulista, talvez devesse ser seguido pelos criadores de obras de imaginação de todos os quadrantes do Brasil, mas sobretudo da Amazônia.

Noutra dimensão, por fim, a obra de Koch-Grünberg também se presta a deslindar o enfrentamento das questões sobre autoria/autoridade/direitos autorais/apropriação e originalidade, que têm como pano de fundo as relações entre ocidentais/brasileiros e índios. Afinal, à diferença do que defendem alguns, é o diálogo, e não o fechamento, a situação enriquecedora das culturas, pois funciona como princípio de fortalecimento das partes. O processo de apropriação realizado pelo etnógrafo alemão se pautou pela ética que se expressa e concretiza na atribuição dos créditos e no reconhecimento da importância e da autoria dos índios Akuli e Mayuluaípu que narraram, traduziram, esclareceram pontos obscuros e foram responsáveis pelo sabor indígena do lendário de que hoje dispomos - e é por isso exatamente que reflui de maneira interessante sobre as culturas brasileira e roraimense, de modo geral, e indígena, em particular.

Mas voltando ao nosso foco para encaminhar a conclusão destas achegas, acrescente-se ainda que, sem ajardinamento antropológico, a obra de Theodor Koch-Grünberg ajudou a evidenciar a participação dos índios na formação da nacionalidade brasileira, a qual enriquecem com sua visão de mundo. Por consequência, contribuiu também para o reconhecimento dos direitos inalienáveis dos índios a viver nas terras que tradicionalmente ocupam, de acordo com suas próprias culturas e desígnios. Prova disso é a arguição do ministro relator do recurso final do processo de demarcação da Terra Indígena Raposa Serra do Sol, Ayres Brito (2009, p. 193), que afirma no arrazoado que escreveu para dar parecer 
João Cezar de Castro Rocha (2012, p. 12) reconhece, no artigo acima citado, a importância de as polêmicas se manterem polêmicas para o desenvolvimento sadio de um sistema intelectual, isto é, de se manterem "inovadoras, capazes de ampliar os problemas, modific a ndo a s respostas anteriormente oferecidas" [mas reconhece que] "uma vez que o sistema esteja solidamente consolidado, o mais prováveléque os debates se limitem a confirmar alianças previamente estabelecidas. O textomatriz transforma-se, então, em mero pretexto para a defesa de posições institucionais". ao processo no 860/2005 que "Até o mito de Macunaíma, que foi recolhido por um alemão, Koch-Grünberg, e transformado por um paulista, M. de Andrade, foi contado por índios daquela área, os Macuxi, os Wapichana. Eles [os índios] são co-autores da ideologia nacional".

O magistrado brasileiro recorreu ao etnógrafo alemão para embasar, na condição de relator, o parecer do processo que demarcou em forma contínua a Terra Indígena Raposa Serra do Sol. Koch-Grünberg contribuiu para o balizamento da decisão da justiça na mais emblemática querela fundiária enfrentada pelos índios brasileiros. E, segundo avalio, um etnógrafo/ antropólogo não poderia pretender logro maior que o de influir por meio da força persuasiva de seu trabalho numa questão do quilate e da magnitude dessa demarcação tão polêmica, porque vazada por interesses de gente muito poderosa.

O caso da opacidade do viajante alemão, segundo entendemos, constitui, a bem da verdade, espécie de miopia típica do nosso sistema de inteligência, uma vez que comprovadamente Theodor Koch-Grünberg tem funcionado para a cultura brasileira como um "autor-matriz", definido por João Cezar de Castro Rocha $(2012$, p. 12) como aquele "cuja obra, pela própria complexidade, autoriza a pluralidade de abordagens, pois elementos diversos de sua obra podem ser valorizados através de articulações teóricas igualmente diversas". Dessa perspectiva, a obra de Koch-Grünberg pode ser concebida na condição de "texto-matriz", uma vez que sua riqueza tem gerado apropriações diversas, quase sempre marcadas pela polêmica. ${ }^{5}$

Este estadoe/ou processo de esquecimento ou apagamento talvez seja indício do caráter da vida intelectual brasileira, cuja memória histórica, curta e lacunar, é acometida, em nossos dias, pela hipertrofia da moda multiculturalista, que podemos designar de "modelo da diversidade". Se por um lado este fenômeno se apresenta como mais uma tentativa de atualização e de desprovincianização da nossa inteligência, por outro desvela, ainda uma vez, a realidade de que a história do desenvolvimento do pensamento brasileiro necessita ser melhor conhecida e aprofundada, a fim de que a nossa diversidade possa de fato assumir um sentido mais crítico, em vez de ser banalizado até gastar toda a sola do sapato e de, assim, ser esvaziado de seu rico conteúdo histórico. 


\section{REFERÊNCIAS}

ANDRADE, Mário de. Macunaíma; o herói sem nenhum caráter. Edição crítica de Telê Porto Ancona Lopez. Rio de Janeiro; São Paulo: LTC; Secretaria da Cultura, Ciência e Tecnologia de São Paulo, 1978, p. 217-224.

Macunaíma. Ed. crítica coord. por Telê Ancona LOPES.

Madrid; Paris; México; Buenos Aires; São Paulo; Lima; Guatemala; San José de Costa Rica; Santiago de Chile, ALLCA XX, 1997.

ARMELLADA, Cesáreo de \& SALAZAR, M. Gutiérrez. Tauron panton. Cuentos y leyendas de los indios pemón. Caracas: Ediciones del Ministério de Éducación, 1989.

BRITTO, Carlos Ayres. Voto do ministro relator. In. MIRA, Julia Trujillo... [ar al.]. Makunaima grita: Terra indígena Raposa serra do Sol e os direitos constitucionais no Brasil. Rio de Janeiro: Beco do Azougue, 2009.

BROTHERSTON, Gordon. La visión americana de la conquista. In. PIZARRO, Ana (Org.). América Latina: Palavra, Literatura e Cultura. São Paulo: Memorial; Campinas: UNICAMP, Vol. 1, 1993, p. 63-84.

FRANK, Erwin H. A construção do espaço étnico roraimense, ou: os Taurepáng existem mesmo? Rev. Antropol. São Paulo, v. 45, n. 2, 2002. Disponível em: <http://www.scielo.br/scielo. php?script=sci_arttext\&pid=S0034- 77012002000200001\&lng=e n\&nrm=iso>. Consultado em 18 de abril de 2009. doi: 10.1590/ S0034-77012002000200001.

Viajar é preciso: Theodor Koch-Grünberg e a Völkerkunde alemã do século XIX. Rev. Antropol., São Paulo, v. 48, n. 2, Dec. 2005. Disponível em: <http://www.scielo.br/scielo. php?script $=$ sci_arttext\&pid=S0034-77012005000200005\&lng $=\mathrm{e}$ n\&nrm=iso $>$. Consultado em 17 de abril de 2009. doi: 10.1590/ S0034-77012005000200005.

KOCH-GRÜNBERG, Theodor. Del Roraima al Orinoco. Mitos y leyendas de los índios Taulipang y Arekuná. Vol. II. Trad. Federica de Ritter. Caracas: Ernesto Armitano, 1989.

Do Roraima ao Orinoco. Observações de uma viagem pelo norte do Brasil e pela Venezuela durante os anos de 1911 a 1913. Vol. III. Etnografia. Trad. Federica de Ritter. Caracas: Ernesto Armitano, 1989b. 
KOCH-GRÜNBERG, Theodor. Dois anos entre nos indígenas. Viagens no noroeste do Brasil (1903/1905). Manaus: EDUA/ FSDB, 2005.

. Do Roraima ao Orinoco. Observações de uma viagem pelo norte do Brasil e pela Venezuela durante os anos de 1911 a 1913. Introdução de Nádia Farage e Paulo Santilli. Tradução Cristina Alberts-Franco. São Paulo: Editora UNESP, 2006.

LOPEZ, Telê Ancona. O turista aprendiz na Amazônia: a invenção no texto e na imagem. An. mus. paul., São Paulo, v. 13, n. 2, Dec. 2005, p. 135-164 [138].

MEDEIROS, Sérgio (Org.). Makunaima e Jurupari. Cosmogonias ameríndias. São Paulo: Perspectiva, 2002.

. A mitologia do viajante solitário. In: MEDEIROS, Sérgio (Org.). Makunaima e Jurupari. Cosmogonias ameríndias. São Paulo: Perspectiva, 2002b.

. Contos confusos? In: MEDEIROS, Sérgio (Org.). Makunaima e Jurupari. Cosmogonias ameríndias. São Paulo: Perspectiva, 2002c.

MIRAS, Julia Trujillo... [et al.]. (Orgs.). Makunaima grita: Terra indígena Raposa Serra do Sol e os direitos constitucionais no Brasil. Rio de Janeiro: Beco do Azougue, 2009.

OLIVEIRA FILHO, João Pacheco. Elementos para uma sociologia dos viajantes. In: OLIVEIRA FILHO, João Pacheco. (Org.) Sociedades indígenas e indigenismo no Brasil. Rio de Janeiro: Marco Zero/Ed. UFRJ, 1987.

PEREIRA, Manuel Nunes. Moronguêtá: um decameron indigena. Rio de Janeiro: Civilização Brasileira, 1980.

PINTO, Renan Freitas. Viagem das ideias. Manaus: Valer, 2005.

PIZARRO, Ana. Imaginario y discurso: la Amazonia. Revista de crítica literaria latinoamericana. Lima-Hanover, ano XXXI, $\mathrm{n}^{\circ}$ 61, 2005, p. 59-74.

PROENÇA, M. Cavalcanti. Roteiro de Macunaíma. 5 ed. Rio de Janeiro: Civilização Brasileira, 1978.

SÁ, Lúcia. Tricksters e metirosos que abalaram a literatura nacional: as narrativas de Akúli e Mayuluaípu. In: MEDEIROS, Sérgio (Org.). Makunaima e Jurupari. Cosmogonias ameríndias. São Paulo: Perspectiva, 2002. 
SÁ, Lúcia. Rain forest literatures. Amazonian texts and latin american culture. Minneapolis/London: University of Minesota Press, 2004.

SALAZAR, M. Gutiérrez. Los pemones y su código ético. Caracas: Universidade Católica Andrés Bello/Hermanos Menores Capuchinos, 2001. . Cultura pemón. Mitología pemón. Guía mítica de la

Gran Sabana. Caracas: Universidade Católica Andrés Bello/ Hermanos Menores Capuchinos, 2002

SANTILLI, Paulo. Pemogon Patá: Território Macuxi, rotas de conflito. São Paulo: Editora UNESP, 2001.

\begin{abstract}
Theodor Koch-Grünberg and the Brazilian culture

In order to demonstrate how the low investment in systematic work and the accumulated knowledge about the diversity of national reality associated with the attachment by new terminology influence on the Brazilian Intelligence system, this essay presents the work of the German ethnographer Theodor Koch-Grünberg - mixture of traveler, linguist, ethnographer, anthropologist and man ofletters - and discusses its place among the constructs of Brazilian Intelligence production.
\end{abstract}

Keywords: Theodor Koch-Grünberg, Brazilian culture, XXth century 